\title{
Erythrovirus B19 infection in acquired immunodeficiency syndrome: screening by histopathology, immunohistochemistry, and in situ hybridization
}

\author{
Sérgio Setúbal/ ${ }^{+}$, Solange Artimos de O liveira, Andréia Rodrigues Cordovil Pires*, \\ Eliene Carvalho da Fonseca*, Luiz Antônio Bastos Camacho**, \\ Ana Cristina Freire Seródio, Jussara Pereira do Nascimento***
}

\begin{abstract}
Departamento de Medicina Clínica, Disciplina de Doenças Infecciosas e Parasitárias ***Departamento de Microbiologia e Parasitologia, Disciplina de Virologia, Instituto Biomédico *Departamento de Patologia, Universidade Federal Fluminense, Rua Marquês de Paraná 303, $2^{\circ}$ andar, 24033-900 Niterói, RJ, Brasil **Departamento de Epidemiologia, Escola Nacional de Saúde Pública-Fiocruz, Rio de Janeiro, RJ, Brasil
\end{abstract}

Erythrovirus B19 infects erythrocytic progenitors, transiently interrupting erythropoiesis. In AIDS patients it causes chronic anemia amenable to treatment. We looked for evidences of B19 infection in stored bone marrow material from patients with acquired immunodeficiency syndrome. Histological sections were made from stored paraffin blocks from 33 autopsies (39 blocks) and 35 biopsies (45 blocks, 30 patients) performed from 1988 to 2002. They were examined after hematoxylin-eosin (HE) staining, immunohistochemical (IHC), and in situ hybridization. $H E$ revealed intra-nuclear inclusion bodies ("lantern cells") suggesting $B 19$ infection in 19 sections corresponding to 19 of 63 patients examined with this test. Seven of 78 sections subjected to immunohistochemistry were positive, corresponding to 7 of 58 patients examined with this test. Fourteen sections corresponding to 13 of the 20 HE and/or IHC positive patients were subjected to in situ hybridization, with six positives results. Among the 13 patients subjected to the three techniques, only one gave unequivocal positive results in all and was considered a true positive. The frequency of B19 infection (1/63 patients) in the material examined can be deemed low.

Key words: parvovirus B19-anemia - chronic-immunodeficiency

Erythrovirus B19 infects human erythrocytic progenitor cells, leading to a transient interruption of erythropoiesis. In the immunocompetent host this viral infection is cleared within two weeks as a result of the appearance of serum specific antibodies, and the hematological manifestations are restricted to a slight and asymptomatic decline in the hemoglobin levels. When the antibodies appear there may be symptoms of immune complex disease like arthralgias and exanthema. This is what normally takes place during the common childhood exanthematic disease erythema infectiosum. The course can be quite different in certain kinds of host, like those with hereditary hemolytic anemias (e.g., sickle-cell anemia), in whom an acceptable hematocrit is maintained only through an intense and uninterrupted bone marrow activity. In this context erythrovirus B19 infection usually leads to the rapid onset of a life threatening acute anemia, the so called "transient aplastic crisis". The patient is transfusion-dependent until the appearance of specific antibodies spontaneously clears the infection. A similar situation can be found in the fetus, where normal erythron volume expan-

Financial support: CNPq (grants 302430/2002-4, 471155/ 2003-9, 520897/96-0, 302622/2003-9), Capes, Faperj (E-26/ $152.009 / 2000)$

${ }^{+}$Corresponding author: labutes@terra.com.br

Received 27 January 2006

Accepted 8 May 2006 sion also demands a high activity of the hematopoietic fetal tissues. The sudden interruption of hematopoiesis leads to fetal heart failure and anasarca (hydrops fetalis), which may result in fetal death. In immunocompromised individuals (e.g., HIV-infected patients) erythrovirus infection is not readily cleared and its long persistence leads to chronic anemia. In these patients, intravenous standard immunoglobulin infusions usually end viremia and restore hematopoiesis (de Mayolo \& Temple 1990, Mitchell et al. 1990, Gottlieb \& Deutsch 1992, Noronha et al. 2005).

Erythrovirus B19 was discovered by chance in 1974, and its cellular tropism and association with the diseases mentioned above were soon described. From 1985 on, papers dealing with co-infection with HIV and erythrovirus B19 began to appear in the literature (Anderson et al. 1985, Mitchell et al. 1990, Chrystie et al. 1990, Frickhofen et al. 1990). In some of them erythrovirus B19 chronic anemia was indeed the initial manifestation of AIDS (Griffin et al. 1991, Gottlieb \& Deutsch 1992, Setúbal et al. 2003). Erythrovirus B19 infection is one cause of anemia in AIDS patients, along with Mycobacterium tuberculosis, $M$. avium-intracellulare, cytomegalovirus, Histoplasma capsulatum, Toxoplasma gondii, lymphoma, vitamin deficiency, treatment with zidovudine and sulfa drugs, and the action of HIV itself on bone marrow accessory cells (Garcia 1996, Abkowitz et al. 1997). As erythrovirus B19 anemia in AIDS patients is amenable to treatment, it may be important to confirm (or rule out) its presence. With the exception of some early papers (Mitchell et al. 1990, Naides et al. 1993, Musiani et al. 1995), active erythrovirus 
B19 infection has been considered uncommon among AIDS patients (Gyllensten et al. 1994, Chernak et al. 1995, van Elsacker-Neile et al. 1996, Vernazza et al. 1996). Its resolution after immune reconstitution due to highly active anti-retroviral therapy (HAART) was described recently (Scapellato et al. 2000, Chen et al. 2001, Nolan et al. 2003). Immunoglobulin treatment can cure the infection and, sometimes and paradoxically, transiently worsen the clinical picture by triggering immune complex symptoms (Frickhofen et al. 1990, Setúbal et al. 2003, Young \& Brown 2004).

Since 1998 we have been studying erythrovirus B19 infection in our HIV infected patients in Hospital Universitário Antônio Pedro (HUAP), Niterói, Rio de Janeiro, Brazil (Aguiar et al. 2001, Setúbal et al. 2003). We have always considered co-infection infrequent and attributed this to the fact that most of our HIV infected patients were under anti-retroviral therapy. In an attempt to establish if this supposed low frequency of infection held true in the pre-HAART era, we decided to investigate erythrovirus B19 infection in stored bone marrow specimens available in our Pathologic Anatomy Service. Such a study would enable us to ascertain the importance of erythrovirus B19 in a period in which anti-retroviral treatment was yet in its beginnings.

In order to find evidence of erythrovirus B19 infection, paraffin-stored bone marrow specimens obtained from AIDS or HIV-positive patients from 1988 to 2002 were subjected to histopathologic examination, immunohistochemistry (IHC), and in situ hybridization (ISH).

\section{MATERIALS AND METHODS}

The registry book of the Pathologic Anatomy Service was searched from January 1st, 1988 to December 31st, 1998 for necropsies and biopsies in which there was any mention to AIDS or HIV infection, either as a clinical suspicion or as a necropsy finding. This was found in 297 of the 4210 necropsies done in this period. However, in only 33 there were stored bone marrow paraffin blocks. As in six necropsies there were two different blocks, the total amount of blocks obtained was 39. During that same period 1324 bone marrow biopsies were performed in 984 patients, 29 of them on 24 AIDS or HIV-positive patients. As five patients were subjected to two biopsies in different dates and as in six biopsies there were two different paraffin blocks, the figure for biopsy blocks retrieved amounted to 35 . Other six biopsies, done in six patients from 1999 to 2002 (ten blocks) were added, since they had "lantern cells" suggestive erythrovirus B19 infection on histopathological examination. Thus, the studied material consisted of 45 paraffin blocks from 35 bone marrow biopsies done on 30 patients and of 39 paraffin blocks from 33 necropsies. These blocks were cut in $5 \mu \mathrm{m}$-thick sections which were mounted in silane treated slides. Conventional hematoxylin-eosin (HE) stained slides were also made, for histopathologic examination. All these $84 \mathrm{sec}-$ tions (corresponding to 63 patients: 52 men and 11 women) were first studied through conventional histopathological examination (HE). Seventy eight of these sections (58 patients) were submitted to immunohistochemistry (IHC). Due to the scarcity of material in some paraffin blocks, in situ hybridization was done only in sections that had tested positive on HE and/or IHC. Scarce material (especially in biopsy blocks) was also the reason we could not perform a PCR test. The Wright-Giemsa-stained smears corresponding to the blocks could not be retrieved. We had also no sera from these patients, as we began to bank our sera only in 2001.

$H E$ - The HE stained sections were examined for "lantern cells". These cells have a glassy intranuclear eosinophilic inclusion body, stained pink or lilac, that displaces the chromatin to the periphery. They are frequent in bone marrow and fetal tissues infected by erythrovirus B19 (Ozawa et al. 1986, Brown 1997, Koduri 1998, Krause et al. 1992, Liu et al. 1997). Giant pronormoblasts, the counterpart of "lantern cells" in bone marrow Wright-Giemsastained smears (Koduri 1998, Krause et al. 1992) were not studied, as these smears were unavailable.

Immunohistochemistry - Smears done with insect cells (Spodoptera frugiperda, Sf9) infected with recombinant baculovirus expressing either VP1 or VP2 erythrovirus B19 capsid proteins (Pereira et al. 2001) were used to standardize the primary antibody dilution, made with Dako B0091 polyclonal anti-VP2 rabbit antibody. The best results were found with the 1:50 dilution. This dilution was then used to test tissue sections. A known B19-positive placenta section was used as positive tissue control, since a B19 positive bone marrow section was not available.

The slides were heated to $60^{\circ} \mathrm{C}$ for $10 \mathrm{~min}$ and dipped in heated xylol during $10 \mathrm{~min}$. They were then sequentially immersed in xylol ( $5 \mathrm{~min}$, thrice), absolute alcohol ( 5 min, twice), $96 \%$ alcohol ( 5 min, twice) and distilled water (a rapid dip, twice), at room temperature. Endogenous peroxidase block was done through dipping the slides into a $3 \%$ hydrogen peroxide diluted in distilled water, under mild magnetic stirring for $30 \mathrm{~min}$ at room temperature, followed by two rapid immersions in water. The slides were then heated at $96^{\circ} \mathrm{C}$ for $30 \mathrm{~min}$ while immersed in a 10 $\mathrm{mM}$ pH 6 citrate solution, left cooling down at room temperature for $20 \mathrm{~min}$ and then dipped twice in TBS (pH 7.4 Tris- $\mathrm{HCl} 0.1 \mathrm{M}, \mathrm{NaCl} 0.2 \mathrm{M}$ and Tween $200.05 \%$ ). They were then covered with a blocking solution (powdered skimmed-milk, $0.3 \mathrm{~g}$; albumin fraction V, $0.3 \mathrm{~g}$; TBS, $30 \mathrm{ml}$ ) and left in a wet chamber at $37^{\circ} \mathrm{C}$ for $1 \mathrm{~h}$. The slides were then covered with a $1 / 50$ polyclonal rabbit anti-B19 antibody solution (Dako B0091, Dako Corporation, California) and left in a wet chamber at $4^{\circ} \mathrm{C}$ overnight. They were washed twice in TBS $(5 \mathrm{~min})$, received one drop of biotinylated swine anti-rabbit antibody solution (Dako LSAB code K0690, Dako) and left in a wet chamber for 30 min at room temperature. After two new washings in TBS ( 5 min, each), they were covered with a streptavidin/peroxidase conjugate (Dako LSAB code K0690) and left at room temperature in a wet chamber for $30 \mathrm{~min}$. After an additional washing in TBS, each slide was covered with a chromogen/substrate solution (Dako, Liquid DAB Chromogen 003222). The development was checked with lowpower microscopy $(200 \times)$. The slides were then immersed in distilled water to block the reaction, washed in another watery bath during $5 \mathrm{~min}$, and counterstained with Harris 
hematoxylin. They were then dehydrated and diaphaned by successive baths in $96^{\circ}$ alcohol, absolute alcohol and xylol, and were finally covered with a cover-slip mounted with synthetic resin Entellan (ProSciTech, Australia).

All sections with a positive result were confirmed with a second immunohistochemistry in which the tests were done in duplicate. The difference between the members of each pair was that the primary rabbit antibody had been replaced by normal rabbit serum in one of them.

In situ hybridization - When available, HE- and/or IHC-positive slides were selected for in situ hybridization testing, which was performed according to Nascimento et al. (1991), with some modifications. Bone marrow sections were digested with $250 \mu \mathrm{g} / \mathrm{ml}$ proteinase K (Sigma) at room temperature. Plasmids employed as probes were pGEM-1/ B19 (kindly supplied by JP Clewley, Central Public Heath Laboratory, Colindale, London), pAT153/CMV-O, pAT153/ CMV-S and pAT153/CMV-V, containing respectively, the HindIII digested genome fragments $\mathrm{O}, \mathrm{S}$, and $\mathrm{V}$ of human cytomegalovirus (kindly supplied by P Greenaway, Public Health Laboratory, Salisbury, England). The CMV plasmids were used as negative controls. Probes were labeled with digoxigenin (Roche) and afterwards purified through exclusion chromatography with PDX 50 (Sigma) diluted in $10 \mathrm{mM}$ pH 7.5 Tris-HCl, $1 \mathrm{mM}$ EDTA and 0.1\% SDS (Maniatis et al. 1982). Developing was done using antidigoxigenin alkaline-phosphatase labeled monoclonal antibody (Roche). Nitroblue tetrazolium and bromo-chloroindolyl-phosphate (Sigma) were used as substrate.

Statistical analysis - Examinations of HE-stained sections were done without knowledge of the IHC results and vice-versa. The agreement between $\mathrm{HE}$ and immunohistochemistry results was assessed by the kappa statistic, a measure of chance-corrected agreement (Fleiss 1973), using the software PEPI 4.0 (Abramson \& Gahlinger 2001).

Ethical Committee approval - This work was approved by the Ethical Committee of Antônio Pedro University Hospital, Fluminense Federal University.

\section{RESULTS}

On HE - There were inclusions ("lantern cells") suggesting erythrovirus B19 infection in 19 out of 84 sections $(22.6 \%)$, each from a different patient (Fig. 1A). According to the criteria described in Table I, six slides were considered strongly positive, seven were considered simply positive and six were considered weakly positive. In one of the strongly positive sections (N96 0240, Fig. 1A) the number of cells showing inclusions was considered very high.

As there were two different paraffin blocks in six biopsies and in six necropsies, and five patients were subjected to two biopsies in different days, the studied material was also considered according to each patient individually (Table II), in order to avoid having the results distorted by repeated positive or negative blocks. There were also discrepancies in the results of different blocks obtained from the same biopsy, which were attributed to sampling error. In building Table II we considered, when there were more than one paraffin block in the same biopsy or in the necropsy, only those that were positive. For biopsies done on different days, the second one was taken into account, as we assumed that the changes found in a second biopsy, done in a patient whose symptoms had persisted and perhaps acquired greater severity, would be more evident. To exam a second biopsy would also allow us to detect those patients infected after the first. Table II shows that six patients $(9.5 \%)$ had had a strongly positive result, seven $(12.7 \%)$ had a simply positive result and six $(9.5 \%)$ had a weakly positive one, according to the grading criteria described in Table I.

Immunohistochemistry - Nine out of 78 sections (Table I) were considereds positive. This correspond to seven among 58 patients. These positive sections were then subjected to a confirmatory immunohistochemistry, done in duplicate as described above. Seven slides were again positive. Thus, the re-examination of the material lowered the number of immunohistochemistry positive slides from nine to seven, corresponding to six patients. The percentage of IHC-positive patients was $10.3 \%$ (6/58).

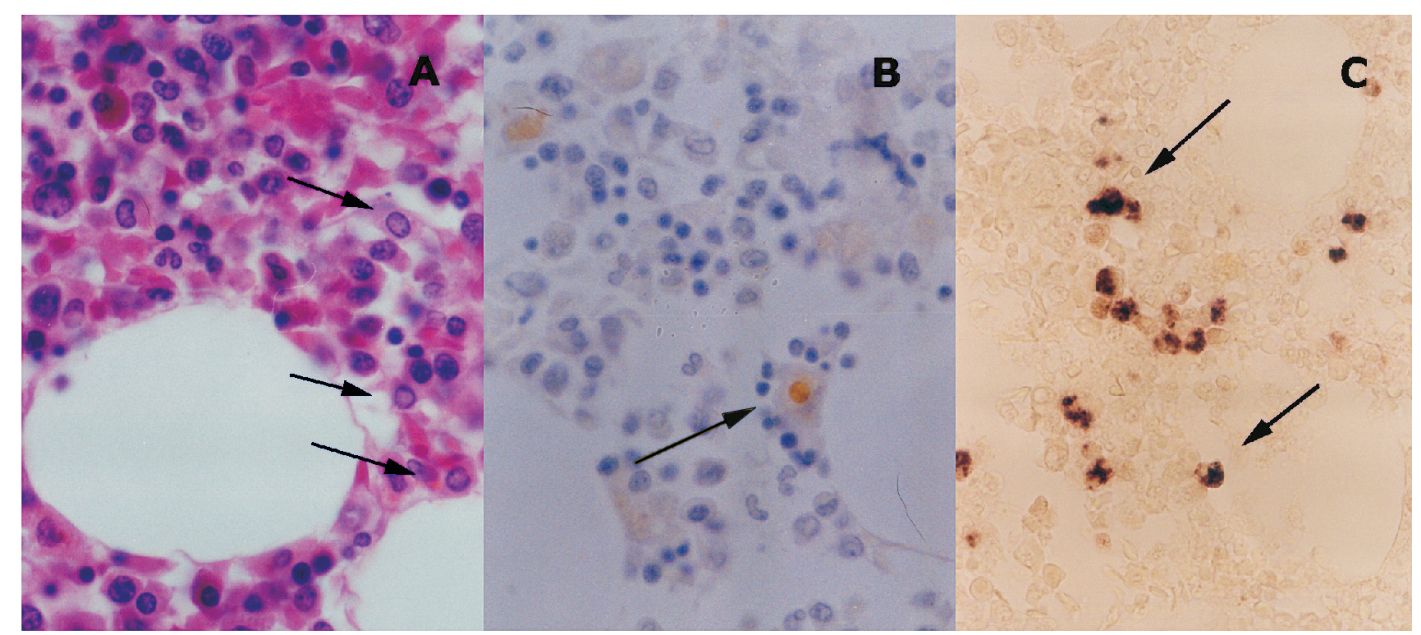

Fig. 1: bone marrow section from necropsy N96-0240 (400 x). A: hematoxylin-eosin staining (arrows: "lantern cells"); B: immunohistochemistry (arrows: B19 antigens); C: in situ hybridization (arrows: B19 DNA). 
TABLE I

Results on hematoxylin-eosin (HE), first and second immunohistochemistry (IHC-1, IHC-2), and in situ hybridization (ISH) examinations done on 22 bone marrow sections from 20 patients

\begin{tabular}{llcccc}
\hline Section $^{a}$ & Patient & HE $^{b}$ & IHC-1 $^{c}$ & IHC-2 $^{c}$ & ISH $^{c}$ \\
\hline B88-0037 & WGV & ++ & + & - & - \\
B97-0770 & VRS & ++ & + & + & - \\
B97-2549-02 & DLT & + & - & ND & - \\
B97-4116 & RSB & + & - & ND & - \\
B97-4258-01 & JRC $d$ & ++ & + & + & - \\
B97-4258-02 & & - & + & - & - \\
B97-4556-01 & FSR $d$ & - & + & + & - \\
B97-4556-02 & & - & + & + & + \\
B99-0848-02 & LMS & +++ & - & ND & ND \\
B99-10073-01 & MGP & + & - & ND & + \\
B00-4353-01 & GAM & ++ & + & + & - \\
B01-1180-02 & PFP & +++ & - & ND & + \\
B01-2969 & SXF & ++ & - & ND & + \\
B02-0005 & DSP & + & - & ND & + \\
N89-0143 & CAR & ++ & + & + & ND \\
N94-0103 & LCEC & +++ & - & ND & ND \\
N94-0244 & BNSF & + & - & ND & ND \\
N95-0281 & CEOG & +++ & - & ND & ND \\
N96-0179-27 & CLGG & + & - & ND & ND \\
N96-0240 & LCM & +++ & + & + & ++ \\
N96-0292 & MSN & +++ & - & ND & - \\
N97-0048-16 & JRS & ++ & - & ND & ND \\
\hline
\end{tabular}

$a$ : sections with an initial B are from biopsies, and sections with an initial $\mathrm{N}$ from necropsies; $b$ : HE-stained sections were considered negative $(-)$, when there where no viral intranuclear inclusions, weakly positive (+) when less than five inclusions were seen in the whole section, strongly positive $(+++)$ when there were inclusions in $\geq 80 \%$ of the medium power fields, and simply positive $(++)$ when they were in an intermediary position between the strongly and weakly positives ones; $c$ : IHC and ISH were negative $(-)$, positive $(+)$ or not done (ND); $d$ : there were two sections for these patients. Sections with negative results in all three kinds of examination were excluded from the Table.

Table III shows that five of the six IHC-positive patients also had positive results on HE examination. Contrariwise, there was a positive HE examination in only 13 of the 51 IHC-negative patients. The observed agreement between these two kinds of examination was $75 \%$. The chance-corrected agreement was 0.31 , whereas the prevalence-adjusted kappa value was 0.51 .

In situ hybridization - Fifteen sections from 13 patients were subjected to in situ hybridization. All ISH results are in Table I, which shows also the HE and IHC results when at least one of them was positive. Six of these 15 sections, each from a different patient, gave positive results being five in agreement with their $\mathrm{HE}$ results and two in agreement to its IHC result. Only one patient (N06-0240) had positive and unequivocal results with all three techniques. It should be noted that among the 20 patients positive by HE and or IHC, five with strong positive result on HE were not available for the ISH test (Table I).
TABLE II

Number of hematoxylin-eosin slides positive for lantern cells, graded according to the amount of cells observed, and the number of patients to which they corresponded

\begin{tabular}{lcc}
\hline Results & Sections & Patients \\
\hline Positive +++ & 6 & 6 \\
Positive ++ & 7 & 7 \\
Positive + & 6 & 6 \\
Negative & 65 & 44 \\
\hline Total of sections/patients & 84 & 63 \\
\hline
\end{tabular}

See Table I for grading criteria.

TABLE III

B19 antigens detection on immunohistochemistry (IHC) according to the presence or absence of lantern cells on hematoxylin-eosin (HE)

\begin{tabular}{lccr}
\hline Patients & Positive on IHC & Negative on IHC & Total \\
\hline Positive +++ on HE & 1 & 5 & 6 \\
Positive ++ on HE & 4 & 2 & 6 \\
Positive + on HE & 0 & 6 & 6 \\
Negative on HE & 1 & 38 & 39 \\
\hline Total & 6 & 51 & 57 \\
\hline
\end{tabular}

Only 57 patients were subjected to both examinations.

Patient records and blood counts - It was not possible to review the records of many patients, for they were often incomplete or simply missing in the hospital archive service. Clinical data could be obtained only in 29 of the 63 patients enrolled in this study. Even so, the records were incomplete, and sometimes the reasons for performing the bone marrow biopsies were not stated. Most patients had anemia, and erythrovirus infection was never mentioned as a possible cause for it. In 16 records there were blood counts done near the date of the biopsies or necropsy. The patient corresponding to necropsy N960240, who had positive results on the three techniques (HE, IHC, and ISH), was not among them. Five patients having blood counts in their records had positive results, two of them on two techniques (HE and IHC) and the remaining three on only one (HE). The mean values for red and white cell count, hematocrit, hemoglobin, and platelets in the blood counts in these five patients were not statistically different from those obtained from the other 11 remaining patients without positive examinations for the erythrovirus B19.

\section{DISCUSSION}

In one of the first systematic studies about co-infection with erythrovirus B19 in a cohort of HIV-positive patients, Anderson et al. (1985) could find neither B19 specific IgM nor B19 DNA (by dot-blot) in the sera of 50 AIDS patients. As in immunocompromised patients the humoral antibody response may be weak or absent (Gyllensten et al. 1994, Anderson et al. 1985), the many case reports, small series of cases, and systematic stud- 
ies that followed (Anderson et al. 1985, Mitchell et al. 1990, Chrystie et al. 1990, Frickhofen et al. 1990, Naides et al. 1993, Gyllensten et al. 1994, Chernak et al. 1995, Musiani et al. 1995, van Elsacker-Neile et al. 1996, Vernazza et al. 1996) used molecular methods for detecting erythrovirus B19 DNA or antigens. The methods more frequently described were immunohistochemistry, dot-blot or in situ hybridization, and PCR. Examination of HE bone marrow biopsy specimens for "lantern cells" and/or bone marrow aspirate smears for giant pronormoblasts were also mentioned by these authors, but most times not recommended as a useful diagnostic method.

Frickhofen et al. (1990) published an account of seven AIDS patients with erythrovirus B19 infection and pure erythrocytic anemia. The diagnosis was confirmed in all seven patients through serum dot-blot hybridization. PCR and ISH detected viral DNA in the bone marrow of three patients in whom this type of specimen was available. The concentration of DNA detected correlated with the number of giant pronormoblasts seen in bone marrow aspirates. On IHC these cells harbored viral antigens.

Using IHC with monoclonal antibody, Morey et al. (1992) detected B19 antigens in sections from paraffinstored tissue of 19 cases of fetal hydrops and one case of persistent infection in an immunodeficient child previously diagnosed by ISH. The number of positive cells in ISH and IHC were approximately the same in each specimen, except in the presence of autolysis, where the number of positive cells in ISH was up to 100 times greater. ISH was a method less susceptible to poor quality of the specimens.

In 1996 Liu et al. (1997) studied 81 bone marrow biopsies and aspirates obtained from 73 patients with AIDS. The biopsies were subjected to monoclonal antibody IHC and ISH and examined after HE staining. Seven were positive on ISH and none on IHC. On HE examination, rare "lantern cells" were found in three ISH-positive specimens. There were no giant pronormoblasts in the four aspirate smears available from the seven ISH-positive cases. There was a fairly reasonable coherence between the findings under HE microscopy and those obtained with ISH. IHC, negative in all cases, was considered insensitive. Although the authors do not mention it, the using of a rather crude decalcification method (chlorhydric acid) may have contributed to the negativity in the IHC and to the low intensity signal in the ISH. Histopathological examination was considered less sensitive than ISH (Liu et al. 1997).

Jordan and Penchansky (1995) found a perfect correlation between the histopathological examination, IHC and PCR in four of 15 cases of acute anemia in children.

Abkowitz et al. (1997) studied 30 HIV-positive patients with hematocrits below $24 \%$, comparing them with controls consisting of $191 \mathrm{HIV}$-positive patients without anemia and 117 healthy male homosexuals. Five viremic individuals were detected among the anemic patients. Interestingly, in a patient with deep anemia there were abundant giant pronormoblasts in the bone marrow aspirate, but no viral DNA could be detected in the serum by dotblot hybridization or PCR. The authors' conclusion was that the presence of giant pronormoblasts is neither sen- sitive nor specific of chronic erythrovirus B19 infection in HIV-positive patients.

Crook et al. (2000) described eight immunodeficient patients in whom the first evidence of erythrovirus B19 infection was the presence of numerous intranuclear inclusions in the bone marrow biopsies. The infections were confirmed by ISH. The authors' conclusion was that the finding of eosinophilic intranuclear inclusions is diagnostic of active erythrovirus B19 infection and warrants confirmation through ISH. This conclusion was opposite to that of Abkowitz et al. (1997).

Heergaard et al. (2002) used PCR for searching erythrovirus B19 DNA in 190 stored bone marrow samples and in the corresponding sera. The viral genome was not found in the sera, but was detected in four of the bone marrow specimens. This was attributed to a resolving infection in one case (a seven years old boy) and to the persistence of the virus in the other three (with ages varying from 47 to 58 years).

It is difficult to decide from all these papers which molecular method should be employed in stored paraffin material. PCR has in its favor its high sensitivity and the relative easiness with which it is performed. Qualitative PCR seems to be adversely affected by its low specificity, as it may result positive in the absence of any clinical significance (Soderlund-Venermo et al. 2002). ISH is cumbersome, time consuming and hard to standardize. IHC seems to be more adversely affected than ISH by the crude decalcification methods employed in the past. This may be important in the study of paraffin blocks stored during many years, as was the case in our present study. These two methods are perhaps complementary and should be done in parallel when HE-stained bone marrow biopsies show intranuclear inclusions, when bone marrow Giemsastained aspirates show giant pronormoblasts or when indicated by the patient's clinical history. Simple as it is, HE examination of bone marrow biopsies may be employed as a screening test in HIV-positive patients with anemia. Indeed, this exam will most times be done to elucidate this clinical problem. The finding of eosinophilic intranuclear inclusions warrants the search of erythrovirus B19 by a molecular method. This should be done even in the absence of histopathological findings if another cause for the anemia cannot be found. This is especially important during periods of high erythrovirus B19 activity in the community to which the patient belongs.

There is, in the medical literature, a wide variation in the number of HIV-positive individuals found to be coinfected with erythrovirus B19 in systematic studies. Bone marrow specimens, which are different from those obtained from other tissues (as they have to be previously decalcified) are not easily worked upon with molecular techniques (Jordan \& Penchansky 1995, Liu et al. 1997). Also, the number of positive cells in bone marrow samples of immunocompromised patients is in general low in comparison to what occurs in the fetus (Crook et al. 2000). Another factor that probably influences the variation seen in the results of different studies is the seasonality of the erythrovirus B19 activity. It is known that this seasonality can greatly influence the frequency of viremic donors (Setúbal et al. 2004), of hydropic fetuses (Valeur-Jensen 
1999), and of individuals with transient aplastic crisis (Serjeant et al. 1981) in a community; there is no reason for it not to influence the frequency of B19 infection in immunodeficient patients as well. The studies most relevant for comparing our results are those of Liu et al. (1997) and of Heergaard et al. (2002), as these authors systematically searched for evidences of erythrovirus B19 infection in paraffin-stored bone marrow specimens. In their studies, the frequency of cases considered to be infected was 8.64 and $2.1 \%$, respectively.

Of the methods employed in our study, the easier to do was microscopic examination of HE-stained slides. The eosinophilic inclusions corresponding to the "lantern cells" were easily seen, and conformed to the descriptions made in the literature (Krause et al. 1992, Crook et al. 2000). However, contrariwise to what was observed by several authors (Barretto-Netto et al. 1988, Crook et al. 2000), the bone marrow samples examined by us were normocellular or hypocellular. Some of the changes described (Barretto-Netto et al. 1988, Krause et al. 1992, Crook et al. 2000) were also frequent in our cases, as the finding of many plasma cells (including numerous Russell bodies), histiocytosis and hyperplasia of megakaryocytes, with immature and dysmorphic forms. Despite the easiness with which HE examination is done and interpreted, the medical literature does not encourage us to consider HE-positivity as a sufficient evidence of erythrovirus B19 infection. To our knowledge, there are no systematic studies that allow to assess the predictive value of this finding in a population similar to that studied by us. We thus tried to validate our findings on HE examinations by having our specimens submitted to IHC and IHS tests.

In the patients subjected to HE examination, the percentage of IHC-positive patients was quite higher among those HE-positive (26.3\%) than among those HE-negative $(2.6 \%)$. If we consider the patients positive on HE and on IHC as having evidence of active B 19 erythrovirus infection, than the frequency of active infection in our patients would be $8.8 \%$ (five of the 57 patients who were subjected to both tests). This frequency, somehow elevated in comparison with the scanty and imperfect literature data, have in its favor the fact that it was generated through the combining of two tests of entirely different nature which had been done blindly. The chance-corrected agreement of these two techniques was fair (prevalence adjusted kappa $=0,52$ ).

We did not consider an isolated positivity on ISH as an evidence of active erythrovirus infection, a case in which the frequency would be at least 6 in 63 , or $9.5 \%$. The presence of small quantities of erythrovirus B19 genome in the bone marrow of the studied patients might explain this high frequency. When the ISH results in the labeling of only few cells, the presence of antigen detectable on IHC would contribute to give significance to the ISH result since an inactive or incomplete genome could not result in the production of antigens, whose presence would indicate an active infection. The exams based on genome (ISH) or antigen (IHC) detection would better be done in parallel (Porter et al. 1990) and it would not be prudent to independently assign to any of them an exclusive significance. By this reason we did not consider pa- tients with positive labeling on few cells only by either IHC or ISH as being actively infected by the erythrovirus B19, a case in which we would have a frequency of at least 9 in 63 or $14.3 \%$. Moreover, among these nine patients, four were positive only on ISH, and three only on IHC. One of them, positive by IHC and ISH, was negative on $\mathrm{HE}$.

According to that, we considered as actively infected only those patients that were positive on $\mathrm{HE}$ and also had unequivocal results on IHC and on ISH. Only one patient had these three prerequisites. This patient died in an advanced stage of AIDS. As there is no external data (clinical, laboratory or of any other class) to validate this result, we can only affirm that this patient, among all patients studied, is the one that has the strongest evidence of active infection, simply because he had, on all three exams, unequivocal and intensely positive results. Accordingly, the frequency of active infection in our studied population was 1 in 63 or $1.6 \%$. This frequency of erythrovirus B19 infection needs confirmation through further, better standardized and prospective investigations, with the help of clinical observation, which was scanty in our study.

\section{ACKNOWLEDGEMENT}

To our technician Valéria Ferreira da Silva.

\section{REFERENCES}

Abkowitz JL, Brown KE, Wood RW, Kovach NL, Green SW, Young NS 1997. Clinical relevance of parvovirus B19 as a cause of anemia in patients with human immunodeficiency virus infection. J Infect Dis 176: 269-273.

Abramson JH, Gahlinger PM 2001. Computer Programs for Epidemiologists: PEPI Version 4.0, Sagebrush Press, Salt Lake City.

Aguiar FS, Lopes DP, Bazin AR, Setúbal S, Cohen BJ, Nascimento JP 2001. Human parvovirus B19 infection in HIV-positive patients. Rev Soc Bras Med Trop 34: 239242.

Anderson MJ, Kidd IM, Jones SE, Pattison JR, Grieco MH, Lange M, Buimovici-Klein E, Cooper LZ 1985. Parvovirus infection and the acquired immunodeficiency syndrome. Ann Intern Med 102: 275.

Barretto Netto M, Vilar EA, Andrade LM, Silva RC, Neves MI 1988. O padrão lesional da medula óssea na imunodeficiência adquirida. Rev Inst Med Trop São Paulo 30: 253-258.

Brown KE 1997. Human parvovirus B19 epidemiology and clinical manifestations. In LJ Anderson, NS Young (eds), Human Parvovirus B19. Monographs in Virology, Vol. 20, Karger, Basel, p. 42-60.

Chen MY, Hung CC, Fang CT, Hsieh SM 2001. Reconstituted immunity against persistent parvovirus B19 infection in a patient with acquired immunodeficiency syndrome after highly active antiretroviral therapy. Clin Infect Dis 32: 13611365 .

Chernak E, Dubin G, Henry D, Naides SJ, Hodinka RL, MacGregor RR, Friedman HM 1995. Infection due to parvovirus B19 in patients infected with human immunodeficiency virus. Clin Infect Dis 20: 170-173.

Chrystie IL, Almeida JD, Welch J 1990. Electron microscopic 
detection of human parvovirus (B19) in a patient with HIV infection. J Med Virol 30:249-252.

Crook TW, Rogers BB, McFarland RD, Kroft SH, Muretto P, Hernandez JA, Latimer MJ, McKenna RW 2000. Unusual bone marrow manifestations of parvovirus B19 infection in immunocompromised patients. Hum Pathol 31: 161-168.

de Mayolo JA, Temple JD 1990. Pure red cell aplasia due to parvovirus B19 infection in a man with HIV infection. South Med J 83: 1480-1481.

Fleiss JL 1973. Statistical Methods for Rates and Proportions, Wiley, New York.

Frickhofen N, Abkowitz JL, Safford M, Berry JM, Antunezde-Mayolo J, Astrow A, Cohen R, Halperin I, King L, Mintzer D 1990. Persistent B19 parvovirus infection in patients infected with human immunodeficiency virus type 1 (HIV-1): a treatable cause of anemia in AIDS. Ann Int Med 113: 926-933.

Garcia MM 1996. La medula ósea (MO) en la infección por el virus de la inmunodeficiencia humana (VIH): La MO en la etiopatogenia de las alteraciones hematológicas asociadas a la infección por el VIH. Sangre 41: 221-230.

Gottlieb F, Deutsch J 1992. Red cell aplasia responsive to immunoglobulin therapy as initial manifestation of human immunodeficiency virus infection. Am J Med 92: 331-333.

Griffin TC, Squires JE, Timmons CF, Buchanan GR 1991. Chronic human parvovirus B19-induced erythroid hypoplasia as the initial manifestation of human immunodeficiency virus infection. J Pediatr 118: 899-901.

Gyllensten K, Sonnerborg A, Jorup-Ronstrom C, Halvarsson M, Yun Z 1994. Parvovirus B19 infection in HIV-1 infected patients with anemia. Infection 22: 356-358.

Heegaard ED, Petersen BL, Heilmann CJ, Hornsleth A 2002. Prevalence of parvovirus B19 and parvovirus V9 DNA and antibodies in paired bone marrow and serum samples from healthy individuals. J Clin Microbiol 40: 933-936.

Jordan JA, Penchansky L 1995. Diagnoses of human parvovirus B19-induced anemia: correlation of bone marrow morphology with molecular diagnosis using PCR and immunocytochemistry. Cell Vision 2: 279-282.

Koduri PR 1998. Novel cytomorphology of the giant proerythroblasts of parvovirus B19 infection. Am J Hematol 58: 95-99.

Krause JR, Penchansky L, Knisely AS 1992. Morphological diagnosis of parvovirus B19 infection. A cytopathic effect easily recognized in air-dried, formalin-fixed bone marrow smears stained with hematoxylin-eosin or Wright-Giemsa. Arch Pathol Lab Med 116: 178-180.

Liu W, Ittmann M, Liu J, Schoentag R, Tierno P, Greco MA, Sidhu G, Nierodzik M, Wieczorek R 1997. Human parvovirus B19 in bone marrows from adults with acquired immunodeficiency syndrome: a comparative study using in situ hybridization and immunohistochemistry. Hum Pathol 28: 760-766.

Maniatis T, Fritsch EF, Sambrook J 1982. Molecular Cloning. A Laboratory Manual, Cold Spring Harbor, New York.

Mitchell SA, Welch JM, Weston-Smith S, Nicholson F, Bradbeer CS 1990. Parvovirus infection and anaemia in a patient with AIDS: case report. Genitourin Med 66: 95-96.
Morey AL, O’Neill HJ, Coyle PV, Fleming KA 1992. Immunohistological detection of human parvovirus B19 in formalin-fixed, paraffin-embedded tissues. J Pathol 166: 105-108.

Musiani M, Zerbini M, Gentilomi G, Rodorigo G, De Rosa V, Gibellini D, Venturoli S, Gallinella G 1995. Persistent B19 parvovirus infections in haemophilic HIV-1 infected patients. J Med Virol 46: 103-108.

Naides SJ, Howard EJ, Swack NS, True CA, Stapleton JT 1993. Parvovirus B19 infection in human immunodeficiency virus type 1-infected persons failing or intolerant to zidovudine therapy. J Infect Dis 168: 101-105.

Nascimento JP, Hallam NF, Mori J, Field AM, Clewley JP, Brown KE, Cohen BJ 1991. Detection of. B19 parvovirus in human fetal tissues by in situ hybridisation. J Med Virol 33: 77-82.

Nolan RC, Chidlow G, French MA 2003. Parvovirus B19 encephalitis presenting as immune restoration disease after highly active antiretroviral therapy for human immunodeficiency virus infection. Clin Infect Dis 36: 1191-1194.

Noronha JT, Martins JC, Leal A, Pone MVS, Campos JMS, Barros ACMW, Garrido JRP, Pone SM, Nascimento JP 2005. Parvovirus B19 associado ao HIV: relato de caso. Rev Soc Bras Med Trop 38: 285.

Ozawa K, Kurtzman G, Young N 1986. Replication of the B19 parvovirus in human bone marrow cell cultures. Science 233: 883-886.

Pereira RF, Paula WN, Cubel RC, Nascimento JP 2001. AntiVP1 and anti-VP2 antibodies detected by immunofluorescence assays in patients with acute human parvovirus B19 infection. Mem Inst Oswaldo Cruz 96: 507-513.

Porter HJ, Heryet A, Quantrill AM, Fleming KA 1990. Combined non-isotopic in situ hybridisation and immunohistochemistry on routine paraffin wax embedded tissue: identification of cell type infected by human parvovirus and demonstration of cytomegalovirus DNA and antigen in renal infection. J Clin Pathol 43: 129-132.

Scapellato PG, Palumbo AM, Del Valle S 2000. Improvement of anemia induced by parvovirus B19 in a patient with AIDS after combined antiretroviral therapy. Mayo Clin Proc 75: 215-216.

Serjeant GR, Topley JM, Mason K, Serjeant BE, Pattison JR, Jones SE, Mohamed R 1981. Outbreak of aplastic crises in sickle cell anaemia associated with parvovirus-like agent. Lancet 2(8247): 595-597.

Setúbal S, Cárdias CAS, Oliveira SA, Nascimento JP 2004. Viremic blood found in a season of high human parvovirus B19 activity in Niterói, Rio de Janeiro, Brazil. Mem Inst Oswaldo Cruz 99: 95-99.

Setúbal S, Jorge-Pereira MC, de Sant'Anna AL, Oliveira SA, Bazin AR, Nascimento JP 2003. Clinical presentation of parvovirus B19 infection in HIV-infected patients with and without AIDS. Rev Soc Bras Med Trop 36: 299-302.

Soderlund-Venermo MK, Hokynar K, Nieminen J, Rautakorpi H, Hedman K 2002. Persistence of human parvovirus B19 in human tissues. Pathol Biol (Paris) 50: 307-316.

Valeur-Jensen AK, Pedersen CB, Westergaard T, Jensen IP, Lebech M, Andersen PK, Aaby P, Pedersen BN, Melbye M 1999. Risk factors for parvovirus B19 infection in pregnancy. JAMA 281: 1099-1105. 
van Elsacker-Neile AM, Kroon FP, van der Ende ME, Salimans MM, Spaan WJ, Kroes AC 1996. Prevalence of parvovirus B19 infection in patients infected with human immunodeficiency virus. Clin Infect Dis 23: 1255-1260.

Vernazza PL, Pfister LA, Siegl G, Cassinotti P 1996. High seroprevalence of parvovirus B19 among patients infected with human immunodeficiency virus. Clin Infect Dis 22: 198-199.

Young NS, Brown KE 2004. Parvovirus B19. New Eng J Med 350: 589-597. 